\title{
Students' Ability in Working the Mathematics Problem
}

\author{
Ni Nyoman Parwati* \\ Department of Mathematics \\ Universitas Pendidikan Ganesha \\ Bali, Indonesia \\ *nyoman.parwati@undiksha.ac.id
}

\begin{abstract}
According to Bloom's taxonomy revised there are 6 levels of cognitive ability as indicators of student learning outcomes. In this study, the abilities studied were limited to the ability to apply concepts. This research is a qualitative descriptive study, with the subject of the research being the eighth-grade students of SMPN 3 Singaraja in the academic year 2018/2019, as many as 30 people. Research data were collected using essay tests. Data analysis was performed descriptively and qualitatively. The results showed that a score of students' abilities in working on application problems an average of 64.67 were in sufficient qualifications. The types of errors made by students in working on the math problem in question include misunderstanding of concepts, misconceptions, arithmetic errors, procedural errors, and errors in understanding symbols. The average of students who made these mistakes, respectively: $27 \%$, $6 \%, 24 \%, 19 \%$, and $10 \%$.
\end{abstract}

Keywords—students' ability, mathematics problem, Bloom's taxonomy

\section{INTRODUCTION}

There are several skills that are needed by students in this 21st century [1], in their book entitled 21st Century Skills: Learning for Life in Our Times, and Akcay and Yager [2], identifies several skills that must be possessed by the $21 \mathrm{st}$ century generation including values and behaviours such as high curiosity, self-confidence, and courage. In addition, there are at least four things that the 21 st century generation must have, namely: ways of thinking, ways of working, tools for working and skills for living in the word. In meeting the demands of 21 st century skills, an educator must have the ability to design learning that is able to deliver students to meet the needs of the 21 st century. The 21 st century abilities that students must have can be described as follows.

Way of thinking. Ways of thinking are some of the thinking skills that students must master to face life in the 21 st century. These thinking abilities include creative thinking, critical thinking, problem solving, decision making and lifelong learning.

Ways of working. The ability how they must work with the global world and the digital world. Some abilities that students must master are communication and collaboration. The $21 \mathrm{st}$ century generation must be able to communicate effectively, using a variety of communication methods and strategies. Able to collaborate and cooperate with individuals and communities and networks. This communication and collaboration network utilizes various ICT-based methods and strategies. How a person must be able to work together with different abilities.

Tools for working. One must own and master the tools for work. Mastery of Information and Communications Technology (ICT) and information literacy is a must. Without ICT and all sources of information, it will be difficult for someone to develop their work.

Skills for living in the world. The ability to live life in the 21st century, namely: Citizenship, life and career, and personal and social responsibility. How learners should live as citizens, life and career, and personal and social responsibilities.

A study conducted by Trilling and Fadel [1] shows that high school, diploma, and higher education graduates are still less competent in terms of: (1) oral and written communication, (2) critical thinking and problem solving, (3) work ethics and professionalism, (4) work in teams and collaborate, (5) work in different groups, (6) use technology, and (7) project management and leadership.

Kivunja [3] and Greenhill [4] identified the competencies and life survival skills needed by students in facing work, and citizenship in the 21 st century emphasized on the following seven (7) skills. (1) critical thinking and problem solving, (2) collaboration and leadership, (3) agility and adaptability, (4) initiative and entrepreneurial spirit, (5) able to communicate effectively both orally and in writing, (6) able to access and analysing information, and (7) having curiosity and imagination.

It can be concluded, through 21 st century learning, there are at least two core skills that must be developed by teachers, including: a) the ability to use knowledge of mathematics, English, Science, and Citizenship to answer real world challenges; and b) critical thinking and problem solving, communication and cooperation, creativity, and independence [4]. 
Mathematics is one of the sciences that has contributed a lot to the development and advancement of other sciences. According to Keller et al [5], there are five standard processes in mathematics, namely, (1) Problem Solving, (2) Reasoning and Proof, (3) Communication, (4) Connections), and (5) Representation.

- Problem Solving Standards, all students should be able to build mathematical knowledge through solving mathematical problems, solve problems that arise in mathematics and in other fields, apply and select various strategies for solving problems, and observe and develop mathematical problem-solving processes.

- The Standard of Reasoning, all students should be able to recognize understanding and evidence as a fundamental aspect of mathematics, make and investigate mathematical conjectures, develop, and evaluate mathematical arguments and evidence, select, and use a variety of understandings and methods of proof.

- Communication Standards, should enable all students to organize and combine their mathematical thinking through communication, communicate their mathematical thinking coherently and clearly to friends, teachers, and others analyse and assess other people's mathematical thinking and strategies, use mathematical language to express mathematical ideas appropriately.

- Connection Standards, should allow all students to recognize and use the connections between mathematical ideas, understand how mathematical ideas are related and interrelated so that they form a complete system, recognize, and apply mathematics in other fields.

- Representation Standards, must enable all students to create and use representations to organize, record, and communicate mathematical ideas; selecting, applying, and realizing mathematical presentations to solve problems; use presentation to model and interpret, physical, social, and mathematical phenomena.

There are several taxonomies of learning outcomes that can be referenced to measure the level of student achievement in following the learning process. One of them is Bloom's taxonomy. Bloom's Taxonomy has undergone revisions from the old version, this revised version has been published since 2001 by Anderson and friends. This revision of Bloom's taxonomy emphasizes the orientation of the competencies needed in the future and how to carry out education that is relevant to the needs of life in this era and in the era to come [6]. This revision of Bloom's taxonomy is a contemporary idea, namely the existence of an intersection between psychoeducation, neurosciences, education, and socio-culture. In the cognitive process dimension, there is a change from the old version, namely: remember, understand, apply, analyse, evaluate, and create. The dimension of knowledge raises four aspects, namely: factual, conceptual, procedural, and metacognitive knowledge. These two dimensions are arranged in the form of a matrix to determine the learning objective design, learning activities, and assessment.

Of the six competencies in the cognitive dimension, one of the most important things to master in learning mathematics is the ability to apply concepts [7]. As a characteristic of application capabilities is being able to apply concepts and principles that are owned in real situations or other situations. When viewed from the level of cognitive abilities, application abilities are included in low or medium level thinking abilities. However, this competence is a necessary condition to be able to master higher-order thinking competencies. Examples of math problems that include measuring the ability of applications for junior high school students are as follows.

Dinda's room is in the shape of a block with a length of 4 meters, a width of 3 meters and a height of 3.5 meters. He wants to paint the walls of his room including windows and doors at an average cost of IDR 75,000 per square meter. How much does it cost to paint Dinda's bedroom walls?

In answering these questions, students need to choose the right procedure related to the surface area of the blocks, then relate it to the amount of costs required for painting. In this case students apply the concept of the surface area of the blocks to solve problems in real life. However, in practice, there are still many students who have not been able to achieve this ability maximally $[7,8]$.

The ability to apply concepts is a very important ability to be mastered by students in learning mathematics. The weakness that often occurs when students learn mathematics is the inability to apply the mathematical concepts they learn in real life, or the use of the mathematical material studied to solve daily life problems [9-11]. Even though in some branches of mathematics it is not always easy to make a connection between mathematics material and its benefits in everyday life However, in learning activities in primary to secondary schools, more meaningful learning activities should be carried out by making links between the mathematics material that students learn in school and its benefits in everyday life. For example, material on geometry, statistics, arithmetic, should be taught by making connections with the application of these materials for everyday life.

Some research results that show the low ability of concept application for students is the research of Koswara and Mundilarto [12] which found that students have difficulty applying mathematical concepts to solve science problems. Furthermore, in his research, it was found that the right strategy was needed so that the students' concept application ability could be improved. The strategy applied was to implement handouts with an emphasis on metacognitive knowledge. Research conducted by Ristiawan [13] found that the ability to apply concepts is something that must be improved in learning mathematics. Furthermore, he said, the weakness that is often found in learning mathematics is not making a connection between the mathematics material being studied and the problems of everyday life. Based on this, research was carried 
out related to increasing the ability to apply mathematical concepts using a realistic mathematics learning approach.

Based on the explanation above and from the results of related research, it is deemed necessary to researching the students' ability to apply mathematical concepts. In this study, it also investigated what types of errors did students make in doing the math problems given? This is done so that in carrying out mathematics learning can emphasize the ability to apply concepts, because it is an important ability for students to master to achieve higher levels of cognitive ability.

\section{METHODS}

This research is a descriptive study with quantitative and qualitative approaches. A descriptive approach was used to describe the average score of students' mathematical concept application ability after taking the concept application ability test. A qualitative approach is taken to get in-depth information related to what types of errors do students make in doing math concept application problems.

The subjects of this study were students of class VIII SMPN 3 Singaraja in the 2018/2019 academic year as many as 30 people who were randomly selected using an intact group. The instruments used in this study were the mathematical concept application ability test and interview guidelines. The test of the ability apply mathematical concepts consists of 5 essay questions in the tangent line of circle teaching material. The research instrument was validated by three validators, namely two lecturers of the Undiksha Mathematics education study program and one mathematics teacher at SMPN 3 Singaraja. The results of the validation are the instruments used to meet the content validity and construction validity. Based on the results of testing the instrument, it was found that the level of reliability of the questions compiled was classified as reliable with a reliability coefficient of 0.85 .

Data collection was carried out by distributing tests of the ability to apply mathematical concepts and conducting interviews with students regarding the mistakes they made in doing the questions. The resulting data is in the form of the average ability of the student's mathematical concept application and a description of the types of errors made by students in answering mathematical concept application questions, the factors that cause students to make mistakes which are known from the results of the researchers' interviews with students.

The data were analysed descriptively by calculating the average score of the students' mathematical concept application ability in the material tangent line of circle and the percentage of the types of errors that were made by the students, as well as conducting a qualitative analysis of the mistakes made by students using the qualitative analysis stage according to Miles and Huberman [14]. Includes: data collection, data reduction, and verification.

\section{RESULTS AND DISCUSSION}

A. Results

Based on the analysis of the test results given to 30 students, the average score for the ability application of the concept in the tangent line of circle material is 64.67, which is in sufficient qualification. The types of errors that students make in this study can be grouped into misunderstanding of concepts (type 1), misconceptions (type 2), arithmetic errors (type 3), procedural errors (type 4), and errors in understanding symbols (type 5). The average students who made these mistakes were: $27 \%, 6 \%, 24 \%, 19 \%$, and $10 \%$, respectively. Misunderstanding of the concept is not being able to make a problem-solving plan appropriately, unable to make interpretations of the problem. Misconceptions are error of conceptions that are consistent in different contexts or problems. Arithmetic errors are errors made to the calculation process. Procedural error is the use of the wrong process. The error in understanding symbols is that students can only describe or pronounce, without being able to use them, as a result all mathematical sentences become meaningless to them so that students manipulate symbols of themselves [15]

The number of students who made mistakes in each question and the type of error made, is presented in Table 1.

TABLE I. TyPES OF ERROR AND The PERCENTAGE OF STUdENTS Who Do IT

\begin{tabular}{|l|l|l|l|l|l|}
\hline \multirow{2}{*}{$\begin{array}{l}\text { Problem } \\
\text { Number }\end{array}$} & \multicolumn{5}{|c|}{ The Number of Students Who Make Errors } \\
\cline { 2 - 6 } & Type & \multicolumn{1}{|c|}{ Type 2 } & Type 3 & Type 4 & Type 5 \\
\hline 1 & 6 & 1 & 2 & 3 & 1 \\
\hline 2 & 8 & 1 & 8 & 4 & 2 \\
\hline 3 & 8 & 2 & 7 & 7 & 2 \\
\hline 4 & 9 & 2 & 9 & 7 & 4 \\
\hline 5 & 10 & 3 & 10 & 8 & 6 \\
\hline $\begin{array}{l}\text { Average } \\
(\%)\end{array}$ & $\mathbf{2 7}$ & $\mathbf{6}$ & $\mathbf{2 4}$ & $\mathbf{1 9}$ & $\mathbf{1 0}$ \\
\hline
\end{tabular}

More clearly, the types of errors that students made and the number of students who did are presented in the graph in Figure 1.

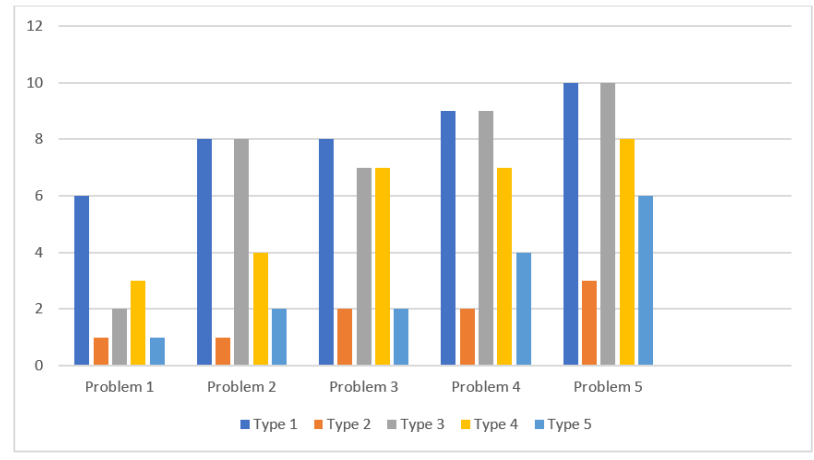

Fig. 1. Graph of the number of students who make errors. 


\section{B. Discussions}

One of the questions given to students is as follows. Gear a bicycle in the form of a circle as shown below.

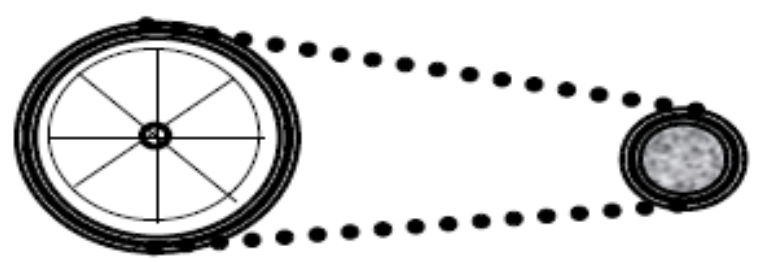

Fig. 2. Bicycle gear.

Based on figure 2, the lengths of the wheel radius are $30 \mathrm{~cm}$ and $10 \mathrm{~cm}$, the distance of wheels centre to each other is $90 \mathrm{~cm}$. How long is the bicycle chain?

Some students answered that the length of the bicycle chain is twice the length of its outer tangent. Interviews were conducted with students who made mistakes like this as follows. R (researchers), S (student).

- R: how do you get the answer if the length of the bicycle chain is related to the length of the tangent to the outer circle?

- $S$ : because I see in the picture there is a tangent to the outer circle, so I think it must be the length of the tangent to the outer circle that is being asked.

- R: how do you get the answer if the length of the bicycle chain is $2 \mathrm{x}$ the length of the outer tangent to the circle?

- $\mathrm{S}$ : I saw in the picture if the length of the chain is the same as the length of the outer tangent to the circle. So, there are two lines like that.

The mistakes made by these students can be categorized as misunderstanding of concepts. In this case, students cannot plan to solve problems properly, cannot make interpretations of the problem. Low understanding of concepts will have an impact on students' problem-solving abilities [15]. Because the heart of learning mathematics is problem solving, to be able to achieve good problem-solving skills is a necessary and sufficient requirement to master the ability of concepts application.

In addition, the mistakes made by these students can also be categorized as errors in understanding the symbol, because students cannot imagine for a fact that the bicycle chain is equal to twice the length of the outer tangent of the two wheels, plus the length of the chain that surrounds half of each these bicycle wheels. Students only know and memorize the formulas but cannot use them properly to solve problems. As a result, students do themself manipulate against the symbols that have been learned.

Examples of student errors that are "arithmetic errors" as in figure 3 .

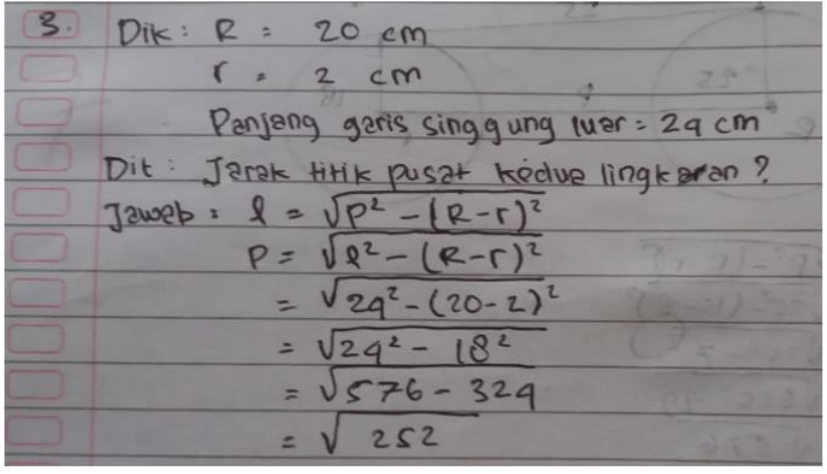

Fig. 3. Arithmetic error of student.

Note:

- Panjang garis singgung luar (The length of outer tangent).

- Jarak titik pusat kedua lingkaran (The distance between the centres of the two circles)

Students have been able to determine the formula correctly. However, when carrying out the calculation process made mistakes in the steps. Not skilled at performing calculations in solving quadratic equations. The calculation that should be done is squaring the first two sides of the equation, then doing the calculations to determine the value of $\mathrm{P}$. After conducting interviews with the student concerned, the following information is obtained. R (researchers), $\mathrm{S}$ (student) as follows.

- R: Can you explain, how did you get the answer like in the second step?

- $\mathrm{S}$ : because the root of $\mathrm{p}$ squared is $\mathrm{p}$. I moved it to the left side. Then I moved the on the left side to the right side so that it became

The problem experienced by these students is that they have been able to determine the formula that will be used in solving the problems at hand. However, it is not skilled when it comes to doing calculations to find the correct answer.

\section{CONCLUSION}

After the text edit has been completed, the paper is ready for the template. Duplicate the template file by using the Save As command and use the naming convention prescribed by your conference for the name of your paper. In this newly created file, highlight all the contents and import your prepared text file. You are now ready to style your paper; use the scroll down window on the left of the MS Word Formatting toolbar.

\section{ACKNOWLEDGMENT}

Thanks are conveyed to DRPM Kemenristek Dikti who has provided research funding assistance. Head of the Buleleng District Youth and Sports Education Office for the permission given to carry out this research. Rector and Chair of the Undiksha LPPM who have approved the implementation of 
this research. The teachers and students at SMPN 3 Singaraja were involved, as well as all parties that could not be mentioned one by one in the success of this research.

\section{REFERENCES}

[1] B. Trilling and C. Fadel, What is 21st Century Learning? 21st Century Skills: Learning for Life in Our Times, 2009.

[2] H. Akcay and R.E. Yager, "The impact of a science/technology/society teaching approach on student learning in five domains," Journal of Science Education and Technology, vol. 19, no. 6, pp. 602-611, 2010.

[3] C. Kivunja, "Do You Want Your Students to Be Job-Ready with 21st Century Skills? Change Pedagogies: A Pedagogical Paradigm Shift from Vygotskyian Social Constructivism to Critical Thinking, Problem Solving and Siemens' Digital Connectivism," International Journal of Higher Education, 2014.

[4] V. Greenhill, 21st Century Knowledge and Skills in Educator Preparation. Partnership for 21 st century skills, 2010.

[5] B.A. Keller, E.W. Hart and W.G. Martin, "Illuminating NCTM's principles and standards for school mathematics," School Science and Mathematics, vol. 101, no. 6, pp. 292-304, 2001.

[6] L.W. Anderson, D.R. Krathwohl and B.S. Bloom, "Revised Bloom's Taxonomy," In A Taxonomy for Learning, Teaching, and Assessing: A Revision of Bloom's Taxonomy of Educational Objectives, 2001.

[7] B.A. Lindsey, P.R. Heron and P.S. Shaffer, "Student ability to apply the concepts of work and energy to extended systems," American Journal of Physics, vol. 77, no. 11, pp. 999-1009, 2009.

[8] E. Van Laar, A.J. Van Deursen, J.A. Van Dijk and J. De Haan, "The relation between 21 st-century skills and digital skills: A systematic literature review," Computers in human behavior, vol. 72, pp. 577-588, 2017.

[9] A.L. Palinussa, "Students' Critical Mathematical Thinking Skills and Character: Experiments for Junior High School Students through Realistic Mathematics Education Culture-Based," Indonesian Mathematical Society Journal on Mathematics Education, vol. 4, no. 1, pp. 75-94, 2013.

[10] S. Sevinc and R. Lesh, "Training mathematics teachers for realistic math problems: a case of modeling-based teacher education courses," ZDM, vol. 50, no. 1, pp. 301-314, 2018.

[11] A. Lady, B.T. Utomo and C. Lovi, "Improving mathematical ability and student learning outcomes through realistic mathematic education (RME) approach," International Journal of Engineering and Technology (UAE), vol. 7, no. 2, pp. 55-57, 2018.

[12] A. Koswara and M. Mundilarto, "Pengembangan handout fluida dinamik terintegrasi metakognisi untuk meningkatkan kemampuan aplikasi siswa SMA dan MA,” Jurnal Inovasi Pendidikan IPA, vol. 4, no. 1, pp. 11-25, 2018.

[13] R. Ristiawan, "Meningkatkan Kemampuan Aplikasi Logika Matematika Melalui Pendekatan Realistik Di SMAN 19 Bekasi," SAP (Susunan Artikel Pendidikan), vol. 3, no. 1, 2018.

[14] M.B. Milles and A.M. Huberman, Analisis data kualitatif: buku sumber tentang metode-metode baru. Jakarta: UIP, 1992.

[15] N. Parwati and I. Suharta, "Effectiveness of the implementation of cognitive conflict strategy assisted by e-service learning to reduce students' mathematical misconceptions," International Journal of Emerging Technologies in Learning (iJET), vol. 15, no. 11, pp. 102-118, 2020. 